\title{
Exposure to malaria affects the regression of hepatosplenomegaly after treatment for Schistosoma mansoni infection in Kenyan children
}

\author{
Mark Booth*1, Birgitte J Vennervald ${ }^{2}$, Anthony E Butterworth ${ }^{3}$, \\ Henry C Kariuki ${ }^{4}$, Clifford Amaganga ${ }^{5}$, Gachuhi Kimani ${ }^{6}$, Joseph K Mwatha ${ }^{6}$, \\ Amos Otedo ${ }^{6}$, John H Ouma ${ }^{7}$ and David W Dunne ${ }^{1}$
}

Address: ${ }^{1}$ Division of Microbiology and Parasitology, Department of Pathology, University of Cambridge, Tennis Court Road, Cambridge, CB2 1QP, UK, ${ }^{2}$ Danish Bilharziasis Laboratory, Jægersborg Alle 1D, 2920 Charlottenlund, Denmark, ${ }^{3}$ Biomedical Research and Training Institute, P.O.Box CY 1753, Causeway, Harare, Zimbabwe, ${ }^{4}$ Division of Vector Borne Diseases, Ministry of Health, P. O Box 54840, Nairobi, Kenya ${ }^{5}$ Kakamega Provincial Hospital, P.O. Box 560, Kakamega, Kenya, ${ }^{6}$ Kenya Medical Research Institute, Nairobi, Kenya and ${ }^{7}$ Maseno University, Kisumu, Kenya

Email: Mark Booth* - mb350@cam.ac.uk; Birgitte J Vennervald - bjv@bilharziasis.dk; Anthony E Butterworth - butterworth@vet.uz.ac.zw; Henry C Kariuki - schisto@wananchi.com; Clifford Amaganga - jmwatha@nairobi.mimcom.net;

Gachuhi Kimani - gkimani@nairobi.mimcom.net; Joseph K Mwatha - jmwatha@nairobi.mimcom.net;

Amos Otedo - jmwatha@nairobi.mimcom.net; John H Ouma - ouma@wananchi.com; David W Dunne - dd@mole.bio.cam.ac.uk

* Corresponding author

Published: 27 September 2004

BMC Medicine 2004, 2:36 doi:10.1186/174|-7015-2-36
Received: 21 May 2004

Accepted: 27 September 2004

This article is available from: http://www.biomedcentral.com/I74I-70I5/2/36

(C) 2004 Booth et al; licensee BioMed Central Ltd.

This is an open-access article distributed under the terms of the Creative Commons Attribution License (http://creativecommons.org/licenses/by/2.0), which permits unrestricted use, distribution, and reproduction in any medium, provided the original work is properly cited.

\begin{abstract}
Background: Schistosoma mansoni and malaria infections are often endemic in the same communities in sub-Saharan Africa, and both have pathological effects on the liver and the spleen. Hepatosplenomegaly associated with S. mansoni is exacerbated in children with relatively high exposure to malaria. Treatment with praziquantel reduces the degree of hepatosplenomegaly, but the condition does not completely resolve in some cases. The present analysis focused on the possibility that exposure to malaria infection may have limited the resolution of hepatosplenomegaly in a cohort of Kenyan schoolchildren.
\end{abstract}

Methods: Ninety-six children aged 6-16, from one community in Makueni district, Kenya, were treated with praziquantel. At baseline, all children had hepatomegaly and most had splenomegaly. The source of $S$. mansoni infection, a river, was molluscicided regularly over the following three years to limit $S$. mansoni re-infection, whereas malaria exposure was uninterrupted. Hepatic and splenic enlargement was assessed annually outside the malaria transmission season.

Results: Children living in an area of relatively high exposure to both infections presented with the largest spleens before treatment and at each follow-up. Spleens of firm consistency were associated with proximity to the river. The regression of hepatomegaly was also affected by location, being minimal in an area with relatively low $\mathrm{S}$. mansoni exposure but high exposure to malaria, and maximal in an area with relatively low exposure to both infections.

Conclusions: The outcome of treating cases of hepatosplenomegaly with praziquantel in this cohort of Kenyan children depended strongly on their level of exposure to malaria infection. Furthermore, a residual burden of hepatosplenic morbidity was observed, which was possibly attributable to the level of exposure to malaria. The results suggest that exposure to malaria infection may be a significant factor affecting the outcome of praziquantel treatment to reduce the level of hepatosplenic morbidity. 


\section{Background}

Hepatosplenomegaly is a widespread but neglected condition affecting many communities in sub-Saharan Africa where both Schistosoma mansoni and malaria infections are endemic. Severely enlarged and hard organs may be an indicator of increased portal pressure, as well as pointing to an increased risk of portal hypertension and its sequelae, including oesophageal varices and haematemesis [1]. Historically, hepatomegaly in sub-Saharan Africa has been associated with $S$. mansoni infection, and on a global scale up to 8.5 million individuals may be affected [2], with the prevalence of organomegaly generally highest in children [3]. Enlargement of spleens has often been associated with the level of malaria transmission [4,5]. One prevailing suggestion has been that hepatosplenomegaly amongst younger children is attributable to malaria infection, whereas older children have acquired some level of immunity to malaria and hence if they do have hepatosplenomegaly it is likely to be attributable to schistosomiasis [6]. However, chronic splenomegaly associated with portal hypertension has been reported in Kenyan hospitals amongst residents from areas where both $S$. mansoni and malaria infections are endemic $[7,8]$, and it has long been suggested that the presence of both infections may confound attempts to quantify the impact of either one $[9,10]$. Recently, it was observed that IgG3 antibody responses to $P$. falciparum schizont antigen (Pfs Ag) were higher in Kenyan children with S. mansoni infection and hepatosplenomegaly compared with children with infection but no hepatosplenomegaly [11], further implicating exposure to malaria in childhood as a risk factor for severe hepatosplenic morbidity.

Given that malaria and schistosome infections are often endemic in the same communities, and are both targets of large-scale but independent, intervention programmes, it is important to understand how continued exposure to one parasite may affect the outcome of intervention against the other. The current longitudinal study evaluated praziquantel treatment on the regression of hepatosplenomegaly amongst children living in an area with endemic $S$. mansoni infection and seasonal malaria infection $[12,13]$. Before treatment, there was a strong correlation between $S$. mansoni egg count and the degree of both hepatomegaly and splenomegaly [12]. However, spatial analysis then revealed heterogeneity in exposure to both infections, and in particular there was an exacerbation of splenomegaly amongst children living in an area of relatively high exposure to both malaria and $S$. mansoni infections [14]. The prevalence of hepatomegaly and splenomegaly decreased slowly during the three-year follow-up period, but had not completely abated by the end of the study [13]. Here, we report that the level of exposure to malaria infection was likely to have been an important factor in limiting the resolution of hepatosplenomegaly in these children.

\section{Methods \\ Study area}

Mbeetwani is situated in the district of Makueni, half way between Nairobi and Mombasa and approximately $10 \mathrm{~km}$ east of the main highway. The ethnic background of the population is predominantly Akamba. During the dry seasons, the river Kambu is the main source of water. Running from west to east, the river lies to the north of the community (Figure 1). Surface water is present at the western end during the dry season, whereas the eastern end is dry and water is retrieved by digging wells into the riverbed. River water is drawn for drinking, cooking and other domestic purposes. Washing of clothes and bathing takes place at numerous sites, and animals are taken to the river to drink.

\section{Clinical examination}

The cohort and examination procedure are described in detail elsewhere [12]. Briefly, 96 children aged between 6 and 16 were selected for ultrasound detectable hepatomegaly after a community survey. They were examined before treatment with praziquantel at $40 \mathrm{mg} / \mathrm{kg}$, and then examined again in the same month in the following three years. Treatment was given again two years into the study. All surveys took place in October of each year, towards the end of the dry season. A total of 67 children attended all examinations, whereas 71 children attended at least the baseline and third year follow-up surveys. Clinical examination consisted of liver and spleen palpation whilst children were in a supine position. Un-palpable spleens and livers were recorded as such, otherwise extensions in $\mathrm{cm}$ below the rib cage along the mid-clavicular line (MCL) and mid sternal line (MSL) were measured for the liver, and extension below the rib cage along the mid-clavicular and mid axillary lines (MAL) was recorded for the spleen. The firmness of each palpable organ was recorded as either soft, firm, or hard, as described previously [12]. An accompanying ultrasound examination was conducted according to World Health Organisation guidelines [15] to test for the presence of periportal fibrosis. Both the clinicians and the ultrasonographers were blinded as to the location of children's domiciles and previous examination results, and the same team performed the examinations throughout the study period.

\section{Mapping}

Details of the mapping procedure are given elsewhere [14]. Briefly, the longitude and latitude of each house were recorded using a Magellan GPS 315 receiver. The course of the river Kambu was determined by taking readings approximately every 100 metres along a ten kilometre stretch that extended beyond the borders of the study 


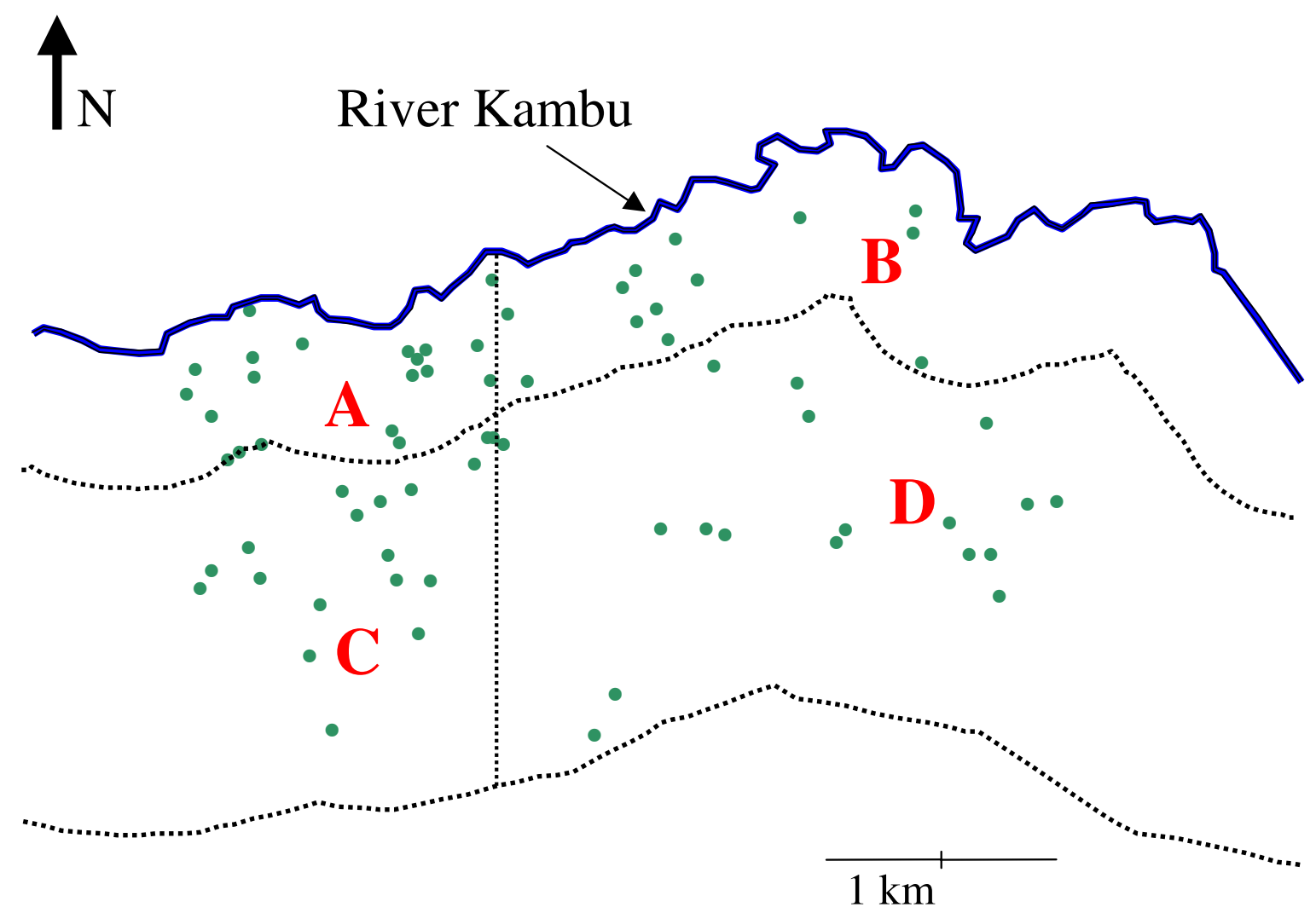

\begin{tabular}{|c|c|c|c|c|c|c|}
\hline & \multicolumn{3}{|c|}{ S. mansoni egg counts } & \multicolumn{3}{|c|}{ IgG3 OD @ 490 nm } \\
\hline Sector & \multicolumn{3}{|c|}{ ( $25 \%$ ile, median, $75 \%$ ile) } & \multicolumn{3}{|c|}{ (25\%ile, median, $75 \%$ ile) } \\
\hline A & 75.8 & 141.7 & 387.5 & 0.089 & 0.145 & 0.199 \\
\hline B & 13.3 & $\mathbf{4 3 . 3}$ & 133.3 & 0.131 & 0.162 & 0.224 \\
\hline C & 39.2 & 140.8 & 312.5 & 0.025 & 0.074 & 0.135 \\
\hline D & 0.0 & 3.3 & 63.3 & 0.044 & $\mathbf{0 . 0 5 3}$ & 0.097 \\
\hline
\end{tabular}

\section{Figure I}

Map of the study area showing the course of the River Kambu, positions of cohort members households and the four sectors corresponding to areas of different exposure to $S$. mansoni and malaria infections. The accompanying table contains the median and $25-75 \%$ ile ranges for egg counts (e.p.g.) before treatment and anti-Pfs IgG3 OD responses for each sector. 
area. The approximately rectangular study area was divided into 4 sectors with similar numbers of houses by bisecting the north-south and east-west transects at $4 \mathrm{~km}$ east of the western boundary and $1 \mathrm{~km}$ south of the river.

\section{Assays}

Since the surveys were undertaken during the dry season, parasitaemia was not expected to provide a good enough estimate of exposure. Therefore, anti-Pfs IgG3 responses were used as a proxy measure of recent exposure [16], measured by ELISA as described previously [17].

\section{Parasitology}

For the quantification of $S$. mansoni eggs, each child provided 3 stool samples before the baseline survey in October 1999. Two $50 \mathrm{mg}$ Kato slides were prepared from each stool sample using the Kato-Katz procedure [18]. All slides were prepared and examined by the same team. Finger-prick blood samples were taken on the same day that clinical and ultrasound examinations were performed, for detection of malaria parasitaemia.

\section{Mollusciciding}

Regular mollusciciding of the river Kambu was undertaken with Bayluscide ${ }^{\circledR}$ (Bayer CropScience AG, AlfredNobel-Str 50, D40789 Monheim am Rhein, Germany). Area-wide application and focal spraying using backpacks was undertaken twice yearly to coincide with periods when snail populations were reduced due to environmental conditions. Snail sampling activities at 9 sites on a monthly basis were undertaken to confirm that snail numbers were kept at very low levels (HC Kariuki, unpublished observations).

\section{Treatment and ethical considerations}

The objectives of the study were carefully explained to the local community including the parents and teachers before the start of any activities. Informed assent was obtained from the parents or guardians of the children. After the clinical and ultrasound examination in October 1999, all children were treated with a single dose of praziquantel (Distocide ${ }^{\circledR}$, Shin Poon Pharmaceuticals, Seoul, Republic of Korea), at $40 \mathrm{mg} / \mathrm{kg}$ body weight. The children were again treated in 2001 and 2002 under the same regimen. No other source of treatment was available locally during this period. Tablets were administered together with a piece of bread and a soft drink in order to minimise gastrointestinal side effects. The study was approved by the Kenya Medical Research Institute Ethical Review Committee.

\section{Analysis}

Baseline data for each parameter were compared with 3 year follow up data amongst 71 children who attended the first and last surveys to estimate the number of chil- dren within each sector who presented with a lower degree of organomegaly at the end of the study. Repeatedmeasures ANOVA of each organ enlargement parameter was also undertaken for the 67 children who attended all surveys, with age, sex and sector of residence as fixed factors. Since ANOVA does not indicate the direction of any change, a post-hoc analysis was undertaken within each sector to determine whether there was an overall increase or decrease in the extent of organomegaly. This was achieved by comparing baseline enlargement and enlargement after 3 years follow up for each parameter, using the Wilcoxon Signed Ranks test. All analyses were conducted in SPSS v11 (SPSS inc, 2001, Chicago).

\section{Results \\ Geographical distribution of exposure}

Figure 1 illustrates the geographical distribution of houses within the study area, as well as the course of the river Kambu. A total of 70 houses were geo-referenced. Also given are the median and 25-75\%ile range of egg counts and anti-Pfs IgG3 responses within each sector before the intervention. Details of the analysis of S. mansoni egg counts and IgG3 responses within each sector are given elsewhere [14]. Briefly, there was a significant clustering of high egg counts in children living at the western end of the study area (Sector A and Sector C). Significant clustering of the highest anti-Pfs IgG3 responses was observed amongst children living in the two northern sectors (Sector A and Sector B). Thus, sector A was an area of relatively high exposure to both infections, sector $B$ was an area of relatively high exposure to malaria only, sector $\mathrm{C}$ was an area of relatively high exposure to $S$. mansoni only, and sector D was an area of low exposure to both infections.

\section{Temporal changes in organ consistency by sector}

Significant variation in the prevalence of hard spleens over time was observed within each sector (Table 1), attributable to an overall decline in the number of children with hard and enlarged spleens (Figure $2 \mathrm{a}$ ). The prevalence of hardened spleens was highest at all time points in the sector with relatively high anti-Pfs IgG3 responses and high egg counts (Sector A). By two years post-treatment, no child resident more than one kilometre from the river presented with a hard spleen.

The prevalence of firm livers in all sectors varied over time, except in sector B (Table 1). In all other sectors there was a decrease in the prevalence of firm livers over the course of the follow-up period (Figure $2 \mathrm{~b}$ ). At the end of the study, the lowest prevalence of firm livers was observed in children from sector D.

\section{Temporal changes in organomegaly by sector}

Significant variation in the degree of MAL splenomegaly was observed in each sector over the three-year follow-up 
Table I: Results of testing for variation in the prevalence of hard spleens and firm livers over time within each sector. Sector is described in the legend to table I. $Q$ - Cochrans $Q$ statistic, $N$ - number of individuals with relevant data from all time points, $p$ - level of significance.

\begin{tabular}{cccccc}
\hline & & Hard spleens & & Firm Livers \\
\hline Sector & $N$ & $Q$ & $p$ & $Q$ & $P$ \\
$A$ & 21 & 14.0 & 0.003 & 13.2 & 0.004 \\
$B$ & 12 & 9.0 & 0.029 & 5.0 & 0.172 \\
C & 15 & 8.3 & 0.041 & 0.8 & 0.049 \\
$D$ & 19 & 12 & 0.007 & 10.7 & 0.013 \\
\hline
\end{tabular}

$(\mathrm{F}=20.7, \mathrm{p}<0.001)$. Figure 3 illustrates a decline in the degree of MAL splenomegaly within each sector, and this was confirmed by post-hoc Wilcoxon Rank analysis (Table $2)$. The rate of regression was affected independently neither by sector, age nor sex, and children from sector A presented with the largest spleens at each time point. At the third year post treatment follow-up, the fraction of each group presenting with no MAL splenomegaly in each sector was 10/24 (Sector A), 6/14 (Sector B), 13/15 (Sector C), and 16/20 (Sector D). MCL splenomegaly also varied significantly over time (Figure $3 \mathrm{~b}, \mathrm{~F}=14.1, \mathrm{p}<0.001$ ), but the extent of variation was affected by sector $(\mathrm{F}=2.191, \mathrm{p}$ $=0.024)$. Post-hoc Wilcoxon rank analysis revealed that there was a significant decrease in the extent of MCL splenomegaly only in sector D (Table 2).

MSL liver enlargement varied significantly over time ( $\mathrm{F}=$ $3.78, \mathrm{p}=0.012)$, with the variation being affected by sector $(\mathrm{F}=2.57, \mathrm{p}=0.008)$. There was no consistent decline in MSL hepatomegaly over time within any one sector (Figure 3c). Although a fraction of the children in each sector presented with reduced hepatomegaly at the third year follow-up, Wilcoxon Rank analysis of the direction of change within each sector confirmed that an overall significant decrease in the extent of MSL hepatomegaly between the baseline survey and the third year follow-up occurred only amongst children from sector D (Table 2). Children from sector B presented with the least improvement in MSL hepatomegaly, with 10/12 exhibiting no change or an increase in this parameter when baseline data were compared with data from the third year followup. MCL hepatomegaly values could not be used in the repeated measures analysis due to a lack of normal variation in the data. Wilcoxon rank analysis within sectors revealed no significant change in this measurement between baseline and the third year follow-up in any sector (Table 2).

\section{Ultrasound results}

There was no evidence of periportal fibrosis in any of the children at any time point.

\section{Discussion}

Many clinical surveys of sub-Saharan communities have reported that organomegaly of the spleen or liver is a very common condition, but attribution to a specific aetiology has always been problematic. Distinguishing the contribution of malaria from that of schistosome infections is particularly complex since they are often endemic in the same communities. However, it is well established that exposure to both $S$. mansoni and malaria varies over small areas [19-21], and the potential therefore exists to compare morbidity in areas of overlapping exposure with areas where infections of one species are more prevalent. Here, we have exploited observations concerning microgeographical variation in the distribution of each infection to demonstrate how the benefits of treatment with praziquantel on hepatosplenomegaly may be affected by local heterogeneity in malaria exposure. Our results further implicate both parasites as aetiological agents of chronic hepatosplenomegaly including firmness of the organs in school-aged children, and have strong implications not only for estimating the burden of S. mansoni and malaria, but also for estimating the outcome of interventions.

The generation of these results was facilitated by several important features of the study design. The intermittent mollusciciding of the river Kambu was particularly important, since it reduced the potential for morbidity to rebound as a result of re-infection, as has been seen elsewhere in studies of both $S$. mansoni and S. haematobium [22]. The timing of the follow-up surveys outside the malaria transmission season was another important component, since it allowed an assessment of the clinical situation without the confounding effects of transient morbidity associated with acute malaria. Without these particular features, it is unlikely that we could have come to any conclusions about the effects of chronic exposure to malaria infection on the regression of hepatosplenomegaly. Another important component of the study was the mapping of both house co-ordinates and the local river. By doing so, we were able to identify spatial clustering of 
$\mathrm{a}$
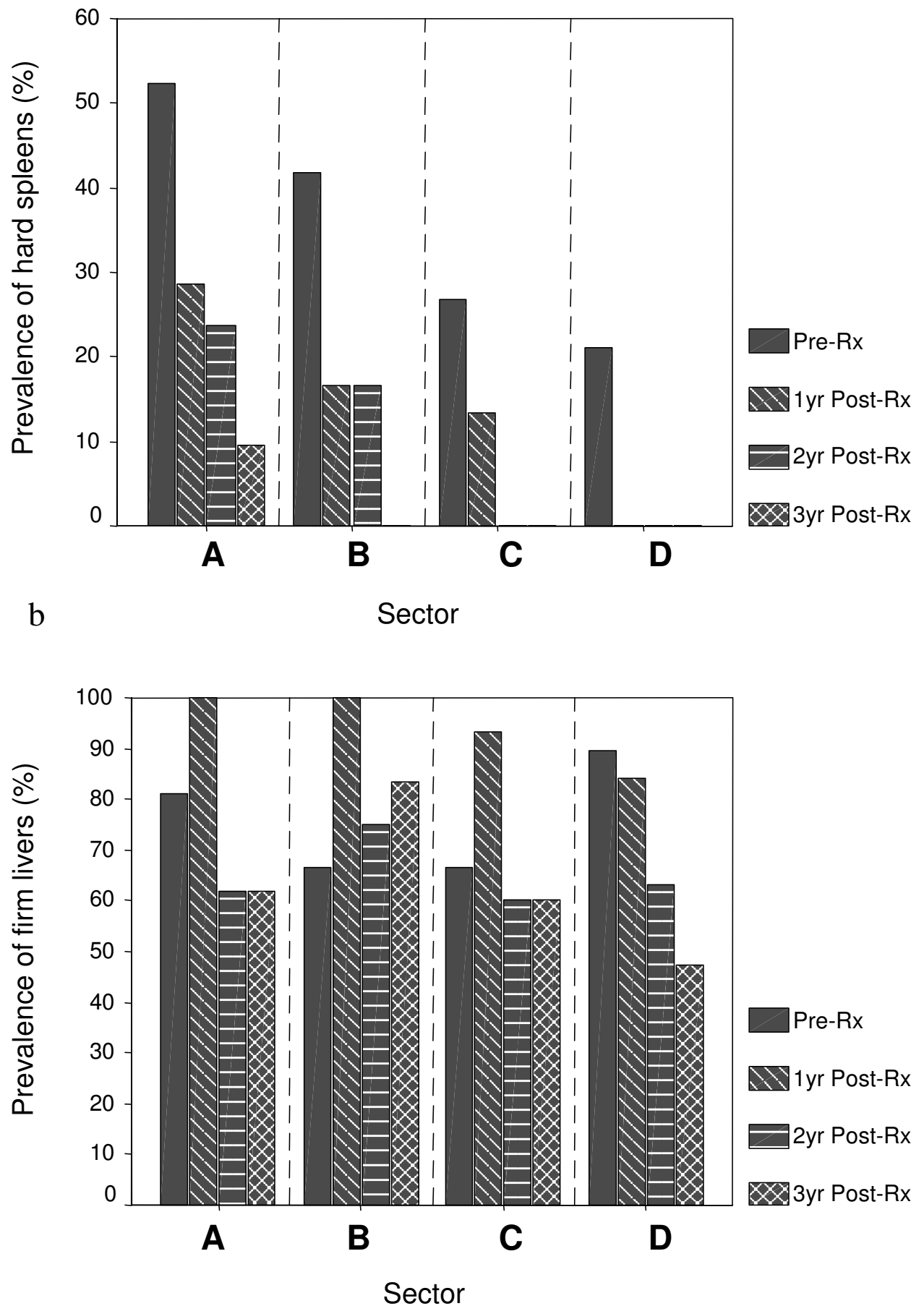

Figure 2

Bar charts depicting temporal (by year) and spatial (by sector) variation in the prevalence of hard spleens (Figure 2a) and firm livers (Figure 2b). Estimates are from the baseline survey and surveys conducted up to three years after first treatment $(\mathrm{Rx})$ with praziquantel. 
$\mathrm{a}$

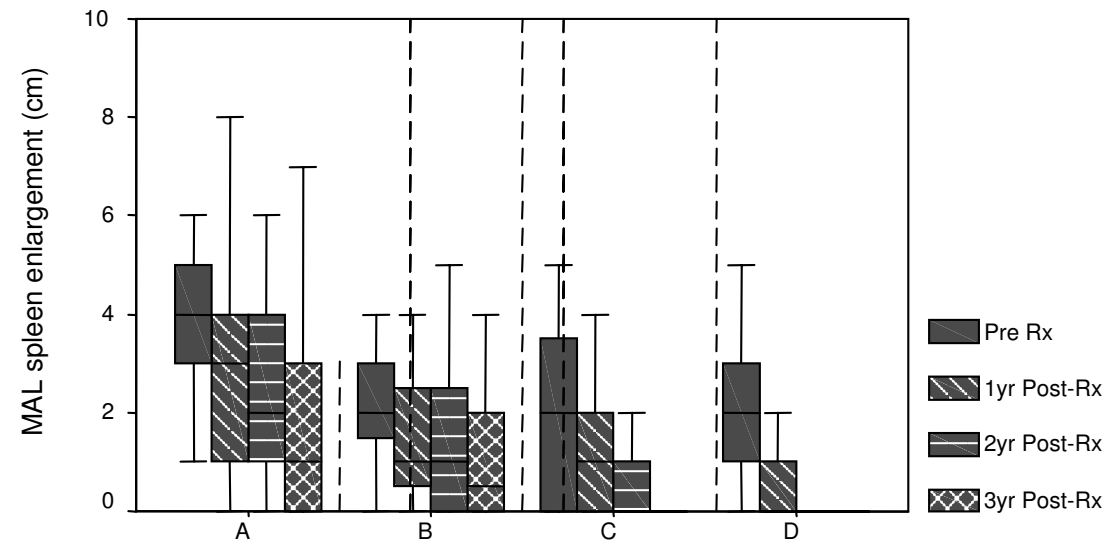

b

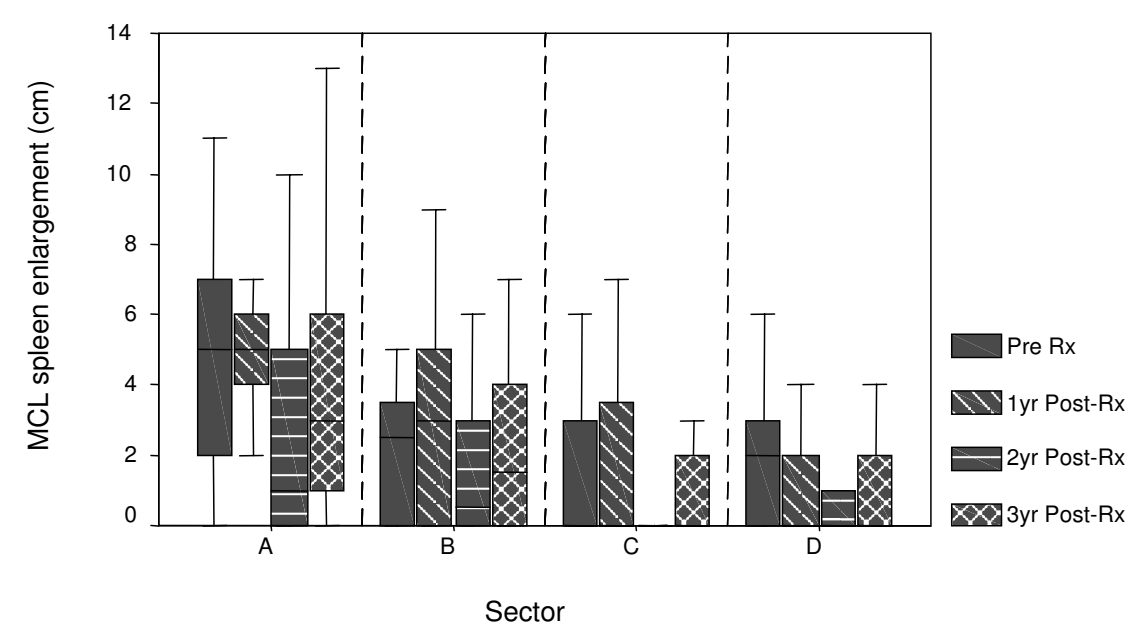

c

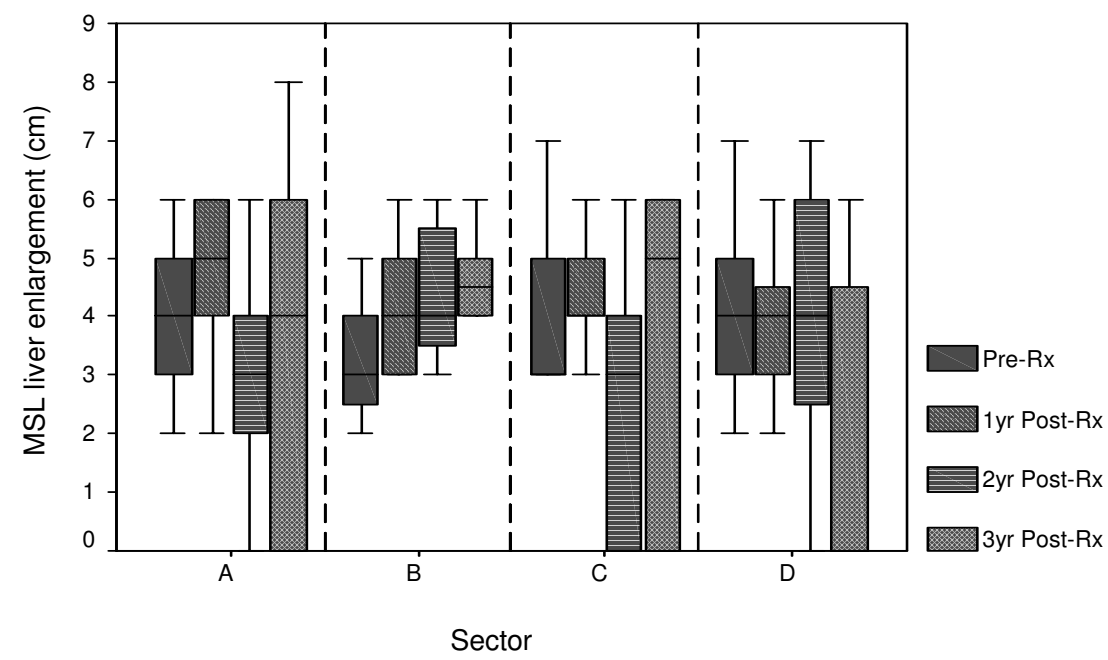

Figure 3

Box and whisker plots depicting temporal (by year) and spatial (by sector) variation in spleen enlargement along the mid axillary line (Figure 3a) and the mid clavicular line (Figure 3b), as well as liver enlargement along the mid sternal line (Figure 3c). The horizontal line within each box represents the median; the lower and upper bounds of the box correspond to the 25- and $75 \%$ iles; the whiskers correspond to the range of non-outlying data. Measurements are from the baseline survey and surveys conducted up to three years after first treatment $(\mathrm{Rx})$ with praziquantel. 
Table 2: Improvement in hepatosplenomegaly stratified by level of exposure to malaria and S. mansoni. Sectors are identified by letter and are described in the text. $N_{i}-$ number of children in each sector with improved organomegaly at the 3 year follow up; $N_{t}-$ total number of children examined at the third year follow-up; Z-Wilcoxon Rank analysis $Z$ score indicating whether or not there was a decrease in the degree of organ enlargement between baseline and the 3 year follow up. A negative $Z$ value and a corresponding $p$ value of $<0.05$ indicates a significant decrease in organ sizes within a given sector.

\begin{tabular}{|c|c|c|c|c|c|c|c|c|c|c|c|c|}
\hline \multirow[b]{2}{*}{ Sector } & \multicolumn{3}{|c|}{ MAL splenomegaly } & \multicolumn{3}{|c|}{ MCL splenomegaly } & \multicolumn{3}{|c|}{ MSL hepatomegaly } & \multicolumn{3}{|c|}{ MCL hepatomegaly } \\
\hline & $N_{i} / N_{t}$ & $Z$ & $p$ & $N_{i} / N_{t}$ & $Z$ & $p$ & $N_{i} / N_{t}$ & $Z$ & $p$ & $N_{i} / N_{t}$ & $Z$ & $p$ \\
\hline$A$ & $21 / 23$ & -3.81 & $<0.001$ & $15 / 23$ & -1.20 & 0.234 & $10 / 23$ & -1.54 & 0.125 & $7 / 23$ & -0.11 & 0.915 \\
\hline$B$ & $9 / 13$ & -2.58 & 0.010 & $5 / 13$ & -0.42 & 0.673 & $2 / 12$ & 1.39 & 0.164 & $1 / 12$ & -1.54 & 0.123 \\
\hline$C$ & $9 / 15$ & -2.72 & 0.007 & $5 / 15$ & -1.13 & 0.260 & $8 / 15$ & -1.22 & 0.222 & $2 / 13$ & -128 & 0.201 \\
\hline$D$ & $18 / 20$ & -3.78 & $<0.001$ & $9 / 20$ & -2.72 & 0.007 & $12 / 20$ & -2.80 & 0.005 & $4 / 20$ & 0.00 & 1.000 \\
\hline
\end{tabular}

relatively high $S$. mansoni egg counts at the western end of the study area. Such clustering is likely related to variation in the amount of surface water along the river, and hence variation in transmission potential due to the strong relationship between snail abundance and water level observed during long term studies of transmission in this area [23]. The clustering of anti-Pfs IgG3 responses to schizont antigen along a tract parallel to the course of the river suggests a sharp decrease in transmission further from the river [14].

Although we observed several significant changes following praziquantel treatment of the cohort, it is important to note that this was a retrospective analysis, which carries a few limitations. The observations made in this study were based on a small, case-only cohort, and therefore do not represent the outcome of an intervention programme involving mass treatment of a population. As this was a retrospective analysis, no control was possible concerning treatment for malaria during the follow-up period. The population had access to antimalarial drugs at local shops, but so far as we are aware there was no systematic intervention against malaria infection during the followup period. The results therefore encompass the effects of background treatment for, as well as exposure to, malaria infections.

Reliability of the clinical measurements is an important factor, especially given the size of the cohort. We have assessed this procedure elsewhere and it has been found to be satisfactory (unpublished observations). The involvement of three or four clinicians at each examination also reduced the degree of imprecision in the organomegaly measurements, and previous analysis has demonstrated that interpretable changes in the measurements occurred within this cohort [13].

The major result from this analysis is that the outcome of treatment with praziquantel, combined with very limited
S. mansoni re-infection, depended strongly on where members of the cohort were resident. Previously, we demonstrated that children within the same cohort that had relatively high-level exposure to both $S$. mansoni and malaria presented with significantly larger spleens before treatment than children highly exposed to either parasite alone [14]. This contrasted with an observation on splenomegaly in school children exposed to malaria only in Ghana, where splenomegaly was observed to decline with distance from mosquito breeding sites [5]. Here, we report that children with relatively large spleens at baseline and living in the area with high levels of exposure to malaria still had the largest spleens 3 years after treatment, despite an overall reduction in their organomegaly.

Hardness of enlarged spleens at baseline was most commonly observed amongst children living close to the river, irrespective of their level of pre-treatment intensity of $S$. mansoni infection [14]. In the absence of follow-up data, the inference may have been that the hard consistency of enlarged spleens was primarily attributable to chronic malaria exposure. However, during the follow-up period, we observed a gradual and monotonic decrease in the prevalence of hard spleens that suggests the removal of $S$. mansoni infection was the trigger for the improvement [13]. One possible explanation is that the hardening of the spleens was due to a synergistic effect of co-infection. Hyperplasia and congestion in the spleen associated with relatively high levels of exposure to malaria may have been sufficient to cause chronic enlargement of the spleen. Hardening and further enlargement may then have occurred as a secondary effect of congestion in the liver attributable to schistosome infection, leading to increased portal pressure and dilation of the splenic vasculature.

Three years after treatment with praziquantel, and with very limited re-infection by $S$. mansoni [12], the prevalence of palpable spleens had diminished considerably. At 
all time points, the prevalence of hard spleens and the degree of splenomegaly were highest amongst children living in the sector with highest egg counts before intervention and highest anti-Pfs IgG3 responses. By removing $S$. mansoni infection and limiting re-infection, we may have abrogated any synergistic effects of co-infection on the spleen, and thereby uncovered the residual burden of chronic exposure to malaria. Importantly, the rate of regression of MAL splenomegaly was not affected significantly by location, which suggests that the effects of praziquantel treatment on splenomegaly attributable to $S$. mansoni infection are not dependent on the level of exposure to either malaria or $S$. mansoni.

The effects of praziquantel treatment on hepatomegaly in this cohort were more subtle. There was gradual decline in the prevalence of hepatomegaly after praziquantel treatment [13] indicating that the removal of S. mansoni infection was a critical factor for improvement. However, upon analysing hepatomegaly data across sectors, it emerged that children from the sector with relatively high anti-Pfs IgG3 responses, but relatively low $S$. mansoni egg counts, had the lowest rate of regression. A possible explanation of this observation is that an aetiological agent other than $S$. mansoni was responsible for the observed hepatomegaly. A likely candidate is malaria infection. Enlargement of the liver in acute malaria infection is temporary and recedes rapidly after treatment [24]; however, studies of young children in Gambia have shown that repeated infection with malaria, perhaps when combined with other unidentified factors, can lead to the development of chronically enlarged livers $[25,26]$. Our observations suggest that even if school-aged children are examined outside the malaria transmission season, they may still be affected by hepatomegaly attributable to malariainfection.

Children from the sector with relatively low exposure to both infections experienced a significant decrease in liver enlargement along the mid sternal line when baseline data were compared with data from the third year followup. It is possible that hepatomegaly in these children was attributable to neither $S$. mansoni nor malaria infection. Alternatively, because they were relatively lightly infected with $S$. mansoni, and experienced relatively low exposure to malaria infection, it is possible that they were more likely to regress in terms of hepatomegaly within the follow-up period.

\section{Conclusions}

In conclusion, our observations lend further support to the hypothesis that severity of hepatosplenomegaly in Kenyan school-aged children is related to their degree of exposure to both S. mansoni and malaria infections. Specifically, although the degree of hepatomegaly or splenomegaly may be correlated with $S$. mansoni infection, there is likely to be further exacerbation of the condition if a child is concurrently exposed to malaria. We have now observed that the apparent benefits of treating a case of hepatosplenomegaly with praziquantel may be reduced if a child lives in an area of relatively high exposure. We have therefore confirmed the long-standing, but untested, hypothesis that co-infections of $S$. mansoni and malaria may obscure the clinical evaluation associated with infection by either species. Our results also introduce the necessity of considering the level of exposure to malaria when evaluating the clinical outcome of praziquantel treatment for $S$. mansoni infection.

\section{Competing interests}

The author(s) declare that they have no competing interests.

\section{Authors' contributions}

$\mathrm{MB}$ conceived of, and conducted, the analysis, and drafted the manuscript. BJV and AEB performed clinical examinations and participated in the design of the study. CA and AO conducted clinical examinations. CHK, GK, JM, JHO and EM participated in the planning and execution of field activities. DWD participated in the design of the study and in fieldwork.

\section{Acknowledgements}

The authors gratefully acknowledge the co-operation of children and teachers from Mbeetwani, as well as the team of fieldworkers. Financial support was obtained from the Wellcome Trust and The Commission of the European Community's Science and Technology for Development Programme (INCO-DC contract ICI8 CT97-0237 and INCO-DEV contract ICA4-CT1999-10003).

\section{References}

I. Richter J, Monteiro Eda S, Braz RM, Abdalla M, Abdel-Rahim IM, Fano $U$, Huntgeburth $U$, Feldmeier H: Sonographic organometry in Brazilian and Sudanese patients with hepatosplenic schistosomiasis mansoni and its relation to the risk of bleeding from oesophageal varices. Acta Trop 1992, 5 I:28I-290.

2. van der Werf MJ, de Vlas SJ, Brooker S, Looman CW, Nagelkerke NJ, Habbema JD, Engels D: Quantification of clinical morbidity associated with schistosome infection in sub-Saharan Africa. Acta Trop 2003, 86: I 25-139.

3. Gryseels B: The morbidity of schistosomiasis mansoni in the Rusizi Plain (Burundi). Trans $R$ Soc Trop Med Hyg 1988, 82:582-587

4. Barnish G, Maude GH, Bockarie MJ, Erunkulu OA, Dumbuya MS, Greenwood BM: Malaria in a rural area of Sierra Leone. II. Parasitological and related results from pre- and post-rains clinical surveys. Ann Trop Med Parasitol 1993, 87: I37-I48.

5. Clarke SE, Bogh C, Brown RC, Walraven GE, Thomas CJ, Lindsay SW: Risk of malaria attacks in Gambian children is greater away from malaria vector breeding sites. Trans $R$ Soc Trop Med Hyg 2002, 96:499-506.

6. Whittle H, Gelfand M, Sampson E, Purvis A, Weber M: Enlarged livers and spleens in an area endemic for malaria and schistosomiasis. Trans $R$ Soc Trop Med Hyg 1969, 63:353-36I.

7. De Cock KM, Awadh S, Raja RS, Wankya BM, Jupp RA, Slavin B, Arap Siongok TK, Rees PH, Bertrand J, Lucas SB: Chronic splenomegaly in Nairobi, Kenya. II. Portal hypertension. Trans R Soc Trop Med Hyg 1987, 81:107-II0. 
8. De Cock KM, Hodgen AN, Lucas SB, Jupp RA, Slavin B, Arap Siongok TK, Rees PH: Chronic splenomegaly in Nairobi, Kenya. I. Epidemiology, malarial antibody and immunoglobulin levels. Trans R Soc Trop Med Hyg 1987, 81: 100-106.

9. Nelson GS: Schistosoma mansoni infection in the West Nile District of Uganda part III. the spleen and S. mansoni infection. East Afr Med J 1958, 35:543-547.

10. Fulford AJ, Mbugua GG, Ouma JH, Kariuki HC, Sturrock RF, Butterworth $\mathrm{AE}$ : Differences in the rate of hepatosplenomegaly due to Schistosoma mansoni infection between two areas in Machakos District, Kenya. Trans R Soc Trop Med Hyg 1991, 85:48I-488.

II. Mwatha JK, Jones FM, Mohamed G, Naus CW, Riley EM, Butterworth AE, Kimani G, Kariuki CH, Ouma JH, Koech D, Dunne DW: Associations between anti-Schistosoma mansoni and anti-Plasmodium falciparum antibody responses and hepatosplenomegaly, in Kenyan schoolchildren. J Infect Dis 2003, I 87: I337-|34|.

12. Vennervald BJ, Kenty LC, Butterworth AE, Kariuki CH, Kadzo H, Ireri E, Amaganga C, Gachuhi K, Mwatha JK, Otedo A, Booth M, Ouma JH, Dunne DW: Detailed clinical and ultrasound examination of children and adolescents in a Schistosoma mansoni endemic area in Kenya: hepatosplenic disease in the absence of portal fibrosis. Trop Med Int Health 2004, 9:46 I-470.

13. Vennervald B, Booth M, Butterworth $\mathrm{AE}$, Kariuki $\mathrm{CH}, \mathrm{Kadzo} \mathrm{H}$, Ireri E, Amaganga C, Gachuhi K, Kenty LC, Mwatha JK, Ouma JH, Dunne DW: Regression of hepatosplenomegaly in Kenyan schoolaged children after praziquantel treatment and in the absence of re-infection by Schistosoma mansoni. Trans $R$ Soc Trop Med Hyg in press.

14. Booth M, Vennervald BJ, Kenty LC, Butterworth $A E$, Kariuki $C H$, Kadzo H, Ireri E, Amaganga C, Gachuhi K, Mwatha JK, Otedo A Ouma J, Dunne DW: Micro-geographical variation in exposure to Schistosoma mansoni and malaria, and exacerbation of splenomegaly in Kenyan school-aged children. BMC Infectious Diseases 2004, 4: I3

15. Richter J, Hatz C, Campagne G, Berquist NR, Jenkins JM: Ultrasound in Schistosomiasis: A Practical Guide to the Standardised Use of Ultrasonogra phy for the Assessment of Schistosomiasis-Related Morbidity Geneva: World Health Organisation; 2000.

16. Kariuki SK, ter Kuile FO, Wannemuehler K, Terlouw DJ, Kolczak MS Hawley WA, Phillips-Howard PA, Orago AS, Nahlen BL, Lal AA, Shi YP: Effects of permethrin-treated bed nets on immunity to malaria in western Kenya I. Antibody responses in pregnant women and cord blood in an area of intense malaria transmission. Am J Trop Med Hyg 2003, 68:6I-67.

17. Naus CW, Jones FM, Satti MZ, Joseph S, Riley EM, Kimani G, Mwatha JK, Kariuki CH, Ouma JH, Kabatereine NB, Vennervald BJ, Dunne DW: Serological responses among individuals in areas where both schistosomiasis and malaria are endemic: cross-reactivity between Schistosoma mansoni and Plasmodium falciparum. J Infect Dis 2003, I 87: I272-1282.

18. Katz N, Chaves A, Pellegrino J: A simple device for quantitative stool thick-smear technique in schistosomiasis mansoni. Rev Inst Med Trop Sao Paulo 1972, I 4:397-400.

19. Kloos H, Fulford AJ, Butterworth AE, Sturrock RF, Ouma JH, Kariuki HC, Thiongo FW, Dalton PR, Klumpp RK: Spatial patterns of human water contact and Schistosoma mansoni transmission and infection in four rural areas in Machakos District, Kenya. Soc Sci Med 1997, 44:949-968.

20. Charlwood JD, Smith T, Lyimo E, Kitua AY, Masanja H, Booth M, Alonso PL, Tanner $\mathrm{M}$ : Incidence of Plasmodium falciparum infection in infants in relation to exposure to sporozoite-infected anophelines. Am J Trop Med Hyg 1998, 59:243-25I.

21. Thomas C], Lindsay SW: Local-scale variation in malaria infection amongst rural Gambian children estimated by satellite remote sensing. Trans $R$ Soc Trop Med Hyg 2000, 94:I59-163.

22. Hatz CF, Vennervald BJ, Nkulila T, Vounatsou $P$, Kombe $Y$, Mayombana C, Mshinda H, Tanner M: Evolution of Schistosoma haematobium-related pathology over 24 months after treatment with praziquantel among school children in southeastern Tanzania. Am J Trop Med Hyg 1998, 59:775-78I.

23. Sturrock RF, Klumpp RK, Ouma JH, Butterworth AE, Fulford AJ, Kar iuki HC, Thiongo FW, Koech D: Observations on the effects of different chemotherapy strategies on the transmission of Schistosoma mansoni in Machakos District, Kenya, measured by long-term snail sampling and cercariometry. Parasitology 1994, I09(Pt4):443-453.

24. Sowunmi A: Hepatomegaly in acute falciparum malaria in children. Trans $R$ Soc Trop Med Hyg 1996, 90:540-542.

25. Davies AH, Gilles HM, Pearson FA, McGregor IA, Walters JH: Effects of heavy and repeated malarial infections on $\mathrm{Gam}$ bian infants and children. $\mathrm{Br}$ Med J 1956, 2:686-962.

26. Walters JH, McGregor IA: The mechanism of malarial hepatomegaly and its relationship to hepatic fibrosis. Trans $R$ Soc Trop Med Hyg 1960, 54:| 35-145.

\section{Pre-publication history}

The pre-publication history for this paper can be accessed here:

http://www.biomedcentral.com/1741-7015/2/36/prepub

Publish with BioMed Central and every scientist can read your work free of charge

"BioMed Central will be the most significant development for disseminating the results of biomedical research in our lifetime. "

Sir Paul Nurse, Cancer Research UK

Your research papers will be:

- available free of charge to the entire biomedical community

- peer reviewed and published immediately upon acceptance

- cited in PubMed and archived on PubMed Central

- yours - you keep the copyright
BioMedcentral 